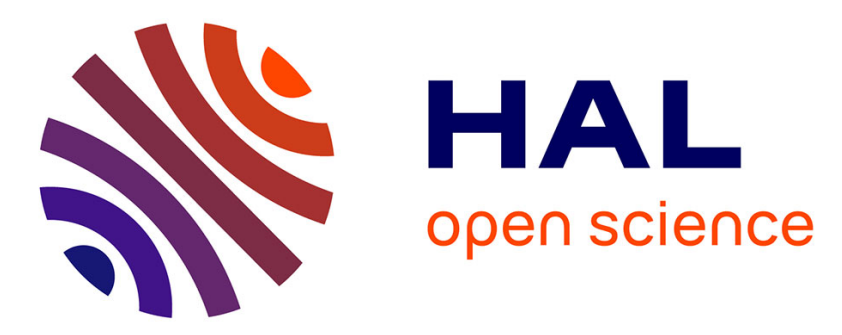

\title{
Suicidal ideation and suicide attempt associated with antidepressant and antiepileptic drugs: Implications for treatment of chronic pain
}

Florian Bailly, Hayat Belaid

\section{- To cite this version:}

Florian Bailly, Hayat Belaid. Suicidal ideation and suicide attempt associated with antidepressant and antiepileptic drugs: Implications for treatment of chronic pain. Joint Bone Spine, 2021, 88 (1), pp.105005. 10.1016/j.jbspin.2020.04.016 . hal-03275510

\section{HAL Id: hal-03275510 \\ https: / hal.sorbonne-universite.fr/hal-03275510}

Submitted on 1 Jul 2021

HAL is a multi-disciplinary open access archive for the deposit and dissemination of scientific research documents, whether they are published or not. The documents may come from teaching and research institutions in France or abroad, or from public or private research centers.
L'archive ouverte pluridisciplinaire HAL, est destinée au dépôt et à la diffusion de documents scientifiques de niveau recherche, publiés ou non, émanant des établissements d'enseignement et de recherche français ou étrangers, des laboratoires publics ou privés. 
Title page informations

Title: Suicidal ideation and suicide attempt associated with antidepressant and antiepileptic drugs: implications for treatment of chronic pain.

Authors and affiliations:

Florian Bailly - Centre d'évaluation et de traitement de la Douleur - Hôpital Pitié Salpêtrière - Paris France

Hayat Belaid - Neurochirurgie - Fondation Ophtalmologique Rotschild - Paris - France

Corresponding author: florian.bailly@aphp.fr

Keywords: chronic pain; opioids; gabapentinoids; pregabalin; gabapentin; misuse; suicide; suicidal ideation

Mots clefs : douleur chronique; opioïdes; gabapentinoïdes; prégabaline; gabapentine; mésusage; idées suicidaires 
Chronic pain is a frequent and disabling condition. Prevalence of chronic pain in a meta-analysis from the UK (1) ranged from $35.0 \%$ to $51.3 \%$, and moderate to severely disabling pain from $10.4 \%$ to 14.3\% Chronic pain is commonly represented by conditions such as back pain, osteoarthritis, neuropathic pain, fibromyalgia, cancer-related pain. While acute pain can be effectively treated using analgesic drugs and managing the aetiology, chronic pain requires a multimodal approach. Analgesics used in acute pain (paracetamol, non-steroidal anti-inflammatory drugs, opioids) are only partially effective for chronic pain. In particular, opioids used in chronic pain can lead to loss of efficacy, physical addiction and misuse with a gradual increase in dosage. The long-term risks are that of overdose and death, which have mostly been described in the U.S. and Canada and been referred to as the "opioid crisis". In 2017, 70,237 drug overdose deaths occurred in the United States. In 2019, the French national drug safety agency (ANSM) published a report on the consumption of opioids, and found that consumption among the European countries, England had the closest situation to the USA (2). In France, between 2006 and 2017, the prescription of strong opioids increased by approximately $150 \%$, and oxycodone is the opioid analgesic with the largest increase (3).

Given the increase of prescription and highlighting the risks associated with these drugs, alternatives to opioid treatments are being sought. Antidepressant and anti-epileptic drugs (AED) are treatments that are being considered.

\section{Increase in the prescription of gabapentinoids and antidepressant used in chronic pain}

In 2016, in the world's top-selling products (ranked by income), pregabalin was the 12th best-selling drug (4). In France, all the data on medicines sold can be analysed using "open medic" database since 2014, issued from the National Health Data System (Système National des Données de Santé) (5).

The description of the number of boxes sold each year in France shows that over the period from 2014 to 2019 (Table 1):

- The prescription of opioid analgesics has decreased by $6.5 \%$.

- All opioids are decreasing, except for oxycodone which has increased by $9.2 \%$.

- The most commonly used antidepressants for pain, venlafaxine and amitriptyline, increased by $12.1 \%$ and $4.3 \%$ respectively.

- Pregabalin and gabapentin increased by $17.5 \%$ and $16.6 \%$.

However, this increase in gabapentinoids in France is less significant than in the USA, where the prescription of gabapentin and especially pregabalin has doubled (6). It has been suggested that gabapentinoids are increasingly being prescribed due to the opioid crisis. For some patients with 
chronic pain, only partially improved by opioids, gabapentinoids are one of the few non-opioid, nonacetaminophen, non-NSAID options (6).

\section{Suicide risk and anti-epileptic drugs}

Pregabalin and gabapentin were initially developed and labelled as AED. They modulate the $\alpha 2 \delta$ subunit of the voltage gated calcium channel present in the central nervous system. The binding sites are present throughout the dorsal spinal cord and brain (7). In animal models of neuropathic pain, gabapentinoids prevent trafficking of the $\alpha 2 \delta 1$ subunit from the dorsal root ganglia neurons to the dorsal spinal cord. Pregabalin and gabapentin were labelled for central and peripheral neuropathic pain. In Europe, pregabalin was also labelled for generalized anxiety disorder, and in the USA for fibromyalgia. Carbamazepine is labelled only for trigeminal neuralgia, and other anti-epileptic drugs are used off-label for neuropathic pain, such as topiramate or lamotrigine. Frequent side-effects of AED are well reported, and the most common are dose dependent and reversible. Central nervous system effects are frequent, such as somnolence, dizziness, fatigue, ataxia and depend on the drug used (8). Change in body weight is the most common chronic side effect (8). Topiramate may cause weight loss whereas carbamazepine, pregabalin and gabapentin may cause weight gain. Suicidal risk was not initially described with anticonvulsant therapy, but in 2008, the Food and Drug Administration (FDA) was concerned about the potential for elevated risk of suicidality (suicidal behaviour or ideation) from the use of antiepileptic drugs and carried out a meta-analysis of 11 AED (9). There were 199 placebo-controlled trials consisting of 27,863 patients in drug arms and 16,029 patients in placebo arms. There were 4 completed suicides among drug patients and none among placebo patients. Overall, patients who received an antiepileptic drug had statistically a significant increased risk of suicidal behaviour or ideation compared to placebo patients (overall odds ratio (OR) $=1.80 ; 95 \% \mathrm{Cl}[1.24,2.66])$. In subgroup analysis, epilepsy had the largest $\mathrm{OR}(3.5395 \% \mathrm{Cl}[1.28$, 12.10 ]), whereas psychiatric indication and other conditions (which included chronic pain) had nonsignificant odds-ratio (OR 1.51; 95\% $\mathrm{Cl}[0.95,2.45]$ and $1.87 ; 95 \% \mathrm{Cl}[0.81,4.76])$. In terms of adjusted risk estimates for the treatment groups, $0.43 \%$ of the drug patients experience suicidal behaviour or ideation compared to $0.24 \%$ of the placebo patients. After this report, AED product information was changed to include warnings about this risk. The European Medicines Agency (EMA) also instituted warnings about AEDs and suicidality. The American report was criticized for concluding that the risk was present for the entire drug class, whereas in the analysis by drug, only topiramate and lamotrigine had a statistically significant risk (10). After this warning, several other studies were conducted in cohorts or databases, which included both patients with neuropathic pain, epilepsy or psychiatric disorders (11). A study in the Danish population estimated the risk of AEDs with a casecrossover design where each case serves at its own control during different periods. Treatment 
initiation was associated with suicide $(\mathrm{OR}=1.8495 \% \mathrm{Cl}[1.36-2.49])$. Individual analysis by drug identified 4 drugs with increased risk (clonazepam, valproate, lamotrigine and phenobarbital), while the other treatments were not significant (12), such as gabapentin $(\mathrm{OR}=2.20 ; 95 \% \mathrm{Cl}[0.83-5.83])$. Pregabalin was not evaluated, due to lack of power. Using the Swedish prescribed drug registry, a population-based cohort has evaluated suicidal behaviour, unintentional overdoses, head/body injuries, road traffic incidents and offences, and arrests for violent crime for people with pregabalin or gabapentin prescription between 2006 and 2013. When the drugs were examined separately, pregabalin was associated with increased hazards of all outcomes, whereas gabapentin was associated with decreased or no statistically significant hazards. Pregabalin hazard ratio (HR) for suicidal behaviour or death by suicide was $1.2695 \% \mathrm{Cl}$ [1.20 - 1.32] whereas gabapentin HR was 1.04 $95 \% \mathrm{Cl}[0.89-1.21]$ (13). Nevertheless, some confounding factors, such as alcohol or illegal drugs, could not be fully considered. These studies, combined with the increasingly documented risk of misuse of gabapentinoids (14), led the British government to classify pregabalin and gabapentin as controlled substances in 2019 (15).

\section{Suicide risk and antidepressant used in chronic pain}

Some antidepressants are indicated in the management of neuropathic pain. Tricyclic antidepressants (TCAs) and serotonin and norepinephrine reuptake inhibitors (SNRIs) have been recommended as first-line treatments (16). In the field of nociplastic pain (such as fibromyalgia) related to a dysfunction of the central nervous system, the management is mainly non-drug based, but may also include antidepressants such as amitryptilline, duloxetine or milnacipran (17). After conducting a meta-analysis for children and adolescent, the FDA issued a black box warning in 2004 regarding an increased risk of suicidal ideation and behaviour. The EMA review of serotonin-selective reuptake inhibitor (SSRI) and SNRI medicines also concluded with a potential risk of suicidal behaviour in children and adolescents treated with these products (18). After expanding his analysis to include adults, the FDA added warnings about the increased risks of suicidal thinking and behaviour in young adults aged 18 to 24 , during the first one to two months following treatment initiation. The proposed labelling changes also state that scientific data did not show such increased risk in adults older than 24 years of age, and that adults 65 years of age and older taking antidepressants have a decreased risk of suicidality(19). A small non psychiatric group of patients was evaluated, which included patients diagnosed with painful diabetic peripheral neuropathy and other types of neuropathic pain, fibromyalgia, and migraine. The rates of suicidal ideation in this group was comparable in subjects administered antidepressants versus placebo $(20,21)$. A review of 
the available data for chronic pain found only data with patients with depression and other indications, without being able to conclude that there is an increased risk in patients with chronic pain (20). However, the "black box warning" in antidepressant drugs lead to significant reductions in antidepressant use within 2 years after the FDA advisory was issued: relative reductions of $31.0 \%$, $24.3 \%$, and $14.5 \%$ among adolescents, young adults, and adults, respectively (22). Moreover, a significant post-warning reduction in the rate of new diagnoses of depression by primary care providers was noticed: $44 \%$ among children, $37 \%$ among young adults, and $29 \%$ among all adults (22).

\section{Implication for chronic pain management}

The management of chronic pain is multifactorial and requires taking care of the patient as a whole. Anxiety and depression are known co-factors in chronic pain, and the risk of suicide is greater in patients with chronic pain (23). It is important to note that suicidal ideations are higher, even after taking into account psychiatric co-morbidities (24). Pain-related catastrophizing is also a risk factor for suicidal ideation in chronic pain (25). Pain management should include an assessment of suicidal risk, both at the time of the initial care and during the follow up. The assessment should also take into account other treatments, such as opioids, which may also be at risk for suicide (26), and benzodiazepines. If a suicide risk has already been identified, antidepressant treatment appears to be more appropriate than AED. Patients should be informed of the increased risk, especially with AED. In deciding whether to initiate or continue antidepressant or antiepileptic drug in chronic pain patients, careful evaluation is necessary to determine whether treatment benefits outweigh risks. Since pain is an independent risk for suicide, comprehensive drug and non-drug management that reduces the intensity of pain and its impact on daily life may also reduce the risk of suicide. 


\begin{tabular}{|c|c|c|c|c|c|c|c|c|c|c|}
\hline & \multicolumn{2}{|c|}{ Gabapentinoids } & \multicolumn{2}{|c|}{ Antidepressant } & \multicolumn{3}{|c|}{ Strong opioids } & \multicolumn{2}{|c|}{ Weak Opioids } & \multirow{2}{*}{$\begin{array}{c}\text { All } \\
\text { opioids }\end{array}$} \\
\hline & $\begin{array}{c}\text { Pregaba } \\
\text { lin }\end{array}$ & $\begin{array}{c}\text { Gabape } \\
\text { ntin }\end{array}$ & $\begin{array}{c}\text { Venlafaxin } \\
\mathrm{e}\end{array}$ & $\begin{array}{c}\text { Amitriptylin } \\
\text { e }\end{array}$ & $\begin{array}{c}\text { Fentan } \\
\text { yl }\end{array}$ & $\begin{array}{l}\text { Oxycod } \\
\text { one }\end{array}$ & $\begin{array}{c}\text { Morphi } \\
\text { ne }\end{array}$ & $\begin{array}{c}\text { Tramado } \\
\text { I }\end{array}$ & Codeine & \\
\hline 2014 & $\begin{array}{c}4784 \\
388\end{array}$ & $\begin{array}{c}1403 \\
344\end{array}$ & 7454672 & 3025205 & $\begin{array}{c}3203 \\
711\end{array}$ & $\begin{array}{c}5481 \\
854\end{array}$ & $\begin{array}{c}7693 \\
007\end{array}$ & $\begin{array}{c}45150 \\
303\end{array}$ & $\begin{array}{c}37478 \\
715\end{array}$ & $\begin{array}{c}99203 \\
039\end{array}$ \\
\hline 2015 & $\begin{array}{c}5177 \\
910\end{array}$ & $\begin{array}{c}1509 \\
620\end{array}$ & 7767012 & 3062015 & $\begin{array}{c}3217 \\
343\end{array}$ & $\begin{array}{c}5531 \\
625\end{array}$ & $\begin{array}{c}7340 \\
308\end{array}$ & $\begin{array}{c}44951 \\
020\end{array}$ & $\begin{array}{c}37580 \\
652\end{array}$ & $\begin{array}{c}98779 \\
642\end{array}$ \\
\hline 2016 & $\begin{array}{c}5331 \\
428\end{array}$ & $\begin{array}{c}1554 \\
007\end{array}$ & 8009567 & 3106646 & $\begin{array}{c}3098 \\
002\end{array}$ & $\begin{array}{c}5304 \\
541\end{array}$ & $\begin{array}{c}6759 \\
900\end{array}$ & $\begin{array}{c}44029 \\
155\end{array}$ & $\begin{array}{c}37402 \\
661\end{array}$ & $\begin{array}{c}96734 \\
533\end{array}$ \\
\hline 2017 & $\begin{array}{c}5425 \\
227\end{array}$ & $\begin{array}{c}1592 \\
675\end{array}$ & 8144218 & 3124058 & $\begin{array}{c}3050 \\
157\end{array}$ & $\begin{array}{c}5628 \\
935\end{array}$ & $\begin{array}{c}7065 \\
459\end{array}$ & $\begin{array}{c}42456 \\
240\end{array}$ & $\begin{array}{c}37436 \\
502\end{array}$ & $\begin{array}{c}95767 \\
898\end{array}$ \\
\hline 2018 & $\begin{array}{c}5621 \\
063\end{array}$ & $\begin{array}{c}1636 \\
060\end{array}$ & 8360196 & 3153902 & $\begin{array}{c}2983 \\
714\end{array}$ & $\begin{array}{c}5988 \\
599\end{array}$ & $\begin{array}{c}7266 \\
910\end{array}$ & $\begin{array}{c}40318 \\
555\end{array}$ & $\begin{array}{c}36123 \\
529\end{array}$ & $\begin{array}{c}92804 \\
260\end{array}$ \\
\hline $\begin{array}{l}\text { Progres } \\
\text { sion } \\
2014 \text { - } \\
2018\end{array}$ & $+17,5 \%$ & $+16,6 \%$ & $+12,1 \%$ & $+4,3 \%$ & $-6,9 \%$ & $+9,2 \%$ & $-5,5 \%$ & $-10,7 \%$ & $-3,6 \%$ & $-6,5 \%$ \\
\hline
\end{tabular}

Table 1: number of boxes of drugs sold each year in France for the main drugs used in chronic pain (analysis using data extracted from the French National Health Data System)

Disclosure of interest:

F Bailly : speaking fees from Grünenthal and Lilly.

$\mathrm{H}$ Belaid : The author declares that she has no competing interest. 
1. Fayaz A, Croft P, Langford RM, Donaldson LJ, Jones GT. Prevalence of chronic pain in the UK: a systematic review and meta-analysis of population studies. BMJ Open. 2016 Jun 1 [cited 2020 Feb 16];6(6).

2. Agence nationale de sécurité du médicament et des produits de santé (ANSM). Use and abuse of opioid analgesics - February 2019 [Internet]. 2019 [cited 2020 Feb 15]. Available from:

https://ansm.sante.fr/content/download/160625/2103379/version/1/file/Rapport_Antalgiques-Opioides_Fev2019_GB.pdf

3. Chenaf C, Kaboré J-L, Delorme J, Pereira B, Mulliez A, Zenut M, et al. Prescription opioid analgesic use in France: Trends and impact on morbidity-mortality. Eur J Pain. 2019 Jan;23(1):124-34.

4. Top 50 pharmaceutical products by global sales - Top Pharma List - PMLiVE [Internet]. 2016 [cited 2020 Feb 8]. Available from: http://www.pmlive.com/top_pharma_list/Top_50_pharmaceutical_products

5. Open Medic : base complète sur les dépenses de médicaments interrégimes - data.gouv.fr [Internet]. [cited 2020 Feb 16]. Available from: /fr/datasets/open-medic-base-complete-sur-les-depenses-de-medicaments-interregimes/

6. Goodman CW, Brett AS. Gabapentin and Pregabalin for Pain - Is Increased Prescribing a Cause for Concern? N Engl J Med. 2017 Aug 3;377(5):411-4.

7. Toth C. Pregabalin: latest safety evidence and clinical implications for the management of neuropathic pain. Therapeutic Advances in Drug Safety. 2014 Feb;5(1):38-56.

8. Perucca E, Meador KJ. Adverse effects of antiepileptic drugs. Acta Neurol Scand. 2005 Dec;112(s181):30-5.

9. Food and Drug Adminstration. Statistical Review and Evaluation Antiepileptic drugs and suicidality [Internet]. 2008 [cited $2020 \mathrm{Feb} 2$ ]. Available from: https://www.fda.gov/files/drugs/published/Statistical-Review-andEvaluation--Antiepileptic-Drugs-and-Suicidality.pdf

10. Britton J. Antiepileptic drugs and suicidality. Drugs, Healthcare and Patient Safety. 2010 Sep;2010:181-9.

11. Pereira A, Gitlin MJ, Gross RA, Posner K, Dworkin RH. Suicidality associated with antiepileptic drugs: Implications for the treatment of neuropathic pain and fibromyalgia: Pain. 2013 Mar;154(3):345-9.

12. Olesen JB, Hansen PR, Erdal J, Abildstrøm SZ, Weeke P, Fosbøl EL, et al. Antiepileptic drugs and risk of suicide: a nationwide study. Pharmacoepidem Drug Safe. 2010;19:518-24.

13. Molero Y, Larsson H, D'Onofrio BM, Sharp DJ, Fazel S. Associations between gabapentinoids and suicidal behaviour, unintentional overdoses, injuries, road traffic incidents, and violent crime: population based cohort study in Sweden. BMJ. 2019 Jun 12;365:12147.

14. Evoy KE, Morrison MD, Saklad SR. Abuse and Misuse of Pregabalin and Gabapentin. Drugs. 2017 Mar;77(4):403-26.

15. Pregabalin and gabapentin to be controlled as class C drugs [Internet]. GOV.UK. [cited 2020 Feb 8]. Available from: https://www.gov.uk/government/news/pregabalin-and-gabapentin-to-be-controlled-as-class-c-drugs

16. Finnerup NB, Attal N, Haroutounian S, McNicol E, Baron R, Dworkin RH, et al. Pharmacotherapy for neuropathic pain in adults: a systematic review and meta-analysis. The Lancet Neurology. 2015 Feb;14(2):16273.

17. Macfarlane GJ, Kronisch C, Dean LE, Atzeni F, Häuser W, Fluß E, et al. EULAR revised recommendations for the management of fibromyalgia. Annals of the Rheumatic Diseases. 2017 Feb 1;76(2):318-28.

18. European Medicines Agency. European Medicines Agency finalises review of antidepressants in childrenand adolescents [Internet]. European Medicines Agency. 2018 [cited 2020 Feb 15]. Available from: 
https://www.ema.europa.eu/en/news/european-medicines-agency-finalises-review-antidepressants-childrenandadolescents

19. Food and Drug Adminstration. Safety Alerts for Human Medical Products - Antidepressant Medication Products [Internet]. [cited $2020 \mathrm{Feb} 23$ ]. Available from: https://wayback.archive-

it.org/7993/20170112170203/http://www.fda.gov/Safety/MedWatch/SafetyInformation/SafetyAlertsforHumanM edicalProducts/ucm150814.htm

20. Pereira A, Conwell Y, Gitlin MJ, Dworkin RH. Suicidal ideation and behavior associated with antidepressant medications: Implications for the treatment of chronic pain: Pain. 2014 Dec;155(12):2471-5.

21. Stone M, Laughren T, Jones ML, Levenson M, Holland PC, Hughes A, et al. Risk of suicidality in clinical trials of antidepressants in adults: analysis of proprietary data submitted to US Food and Drug Administration. BMJ. 2009 Aug 11;339(aug11 2):b2880-b2880.

22. Friedman RA. Antidepressants' Black-Box Warning - 10 Years Later. New England Journal of Medicine. 2014 Oct 30;371(18):1666-8.

23. Calati R, Laglaoui Bakhiyi C, Artero S, Ilgen M, Courtet P. The impact of physical pain on suicidal thoughts and behaviors: Meta-analyses. Journal of Psychiatric Research. 2015 Dec;71:16-32.

24. Braden JB, Sullivan MD. Suicidal Thoughts and Behavior Among Adults With Self-Reported Pain Conditions in the National Comorbidity Survey Replication. The Journal of Pain. 2008 Dec;9(12):1106-15.

25. Edwards RR, Smith MT, Kudel I, Haythornthwaite J. Pain-related catastrophizing as a risk factor for suicidal ideation in chronic pain: Pain. 2006 Dec;126(1):272-9.

26. Ashrafioun L, Bishop TM, Conner KR, Pigeon WR. Frequency of prescription opioid misuse and suicidal ideation, planning, and attempts. Journal of Psychiatric Research. 2017 Sep;92:1-7. 